\title{
Dampak Sektor Transportasi Terhadap Perekonomian di Timor Barat: Suatu Analisis Model Input - Output (I-0)
}

\author{
The Impact of Transportation Sector to Economic on West Timor: An Input- \\ Output Model Analysis
}

\section{Thobias Arnoldus Messakh1}

Program Studi IImu Perencanaan Pembangunan Wilayah dan Pedesaan, Institut Pertanian Bogor Bogor, Indonesia

\section{Ernan Rustiadi}

Divisi Perencanaan dan Pengembangan Wilayah, Departemen Ilmu Tanah dan Sumberdaya Lahan Fakultas Pertanian, Institut Pertanian Bogor, Bogor, Indonesia

\section{Eka Intan Kumala Putri}

Departemen Ekonomi Sumber Daya Lingkungan, Institut Pertanian Bogor, Bogor, Indonesia

\section{Akhmad Fauzi}

Program Studi IImu Perencanaan Pembangunan Wilayah dan Pedesaan, Institut Pertanian Bogor Bogor, Indonesia

Artikel Masuk : 25 September 2020

Artikel Diterima : 9 Juni 2021

Tersedia Online : 31 Agustus 2021

\begin{abstract}
Abstrak: Pembangunan sektor transportasi di Timor Barat diharapkan menjadi mesin penggerak dalam mendukung sektor lainnya, sehingga memberi dampak multipler yang besar bagi perekonomian di perbatasan darat negara dengan Timor Leste. Pemerintah perlu melakukan terobosan pembangunan sektor transportasi, oleh karena Timor Barat mengalami defisit infrastruktur transportasi. Hal ini karena masih rendahnya kualitas dan kuantitas infrastruktur transportasi yang mampu mendukung perekonomian wilayah. Penelitian ini bertujuan untuk mengkaji dampak ke belakang, dampak ke depan, serta dampak pengganda pembangunan di Timor Barat pada tahun 2018. Analisis menggunakan analisis input-output dengan data dasar input output Nusa Tenggara Timur (NTT) tahun 2006. Data tersebut diagregasi dari 55 sektor menjadi 18 sektor untuk Timor Barat. Hasil penelitian menunjukkan bahwa sektor transportasi di Timor Barat memiliki: derajat penyebaran sebesar 1,40; derajat kepekaan sebesar 0,486; dampak berganda (multiplier effect) terhadap gaji dan upah (multiplier income) sebesar 2,069; serta dampak terhadap nilai tambah total (total value added multiplier) sebesar 1,409. Sektor transportasi perlu dioptimalkan dengan membangun konektivitas antara moda jaringan transportasi yang lebih efektif dan efisien. Selain itu, perlu
\end{abstract}

\footnotetext{
1 Korespondensi Penulis: Program Studi Ilmu Perencanaan Pembangunan Wilayah dan Pedesaan Institut Pertanian Bogor, Bogor, Indonesia Email: messakh_thomy69@apps.ipb.ac.id
} 


\title{
128 Dampak Sektor Transportasi Terhadap Perekonomian di Timor Barat . . .
}

mengoptimalkan konektivitas dalam mengintegrasi tahapan pembangunan ruas jalan nasional, provinsi dan kabupaten. Konektivitas jaringan tersebut diharapkan dapat mendorong sektor produksi yang mampu meningkatkan atau mengembangkan kapasitas produksi, sehingga memberi dampak pengganda yang lebih optimal ke depan.

Kata Kunci: dampak sektor transportasi; input-output; multiplier income; Timor Barat

\begin{abstract}
The development of the transportation sector on the West Timor is expected to be a driving machine in supporting other sectors, so that it will have a large multipler impact on the economy at the land borders of the country with Timor Leste. The government needs to make breakthroughs in the development of the transportation sector, because West Timor is experiencing a transportation infrastructure deficit. This is due to the low quality and quantity of transportation infrastructure capable of supporting the regional economy. This study aims to examine the impact backward and forward, as well as the multiplier impact of development on West Timor in 2018. The result of the researched was that the transportation sector in West Timor has a degree of distribution of 1.40. While the degree of sensitivity was 0.486 . The multiplier effect on salaries and wages (multiplier income) is 2.069, and the impact on the total value added multiplier is 1.409. The transportation sector needs to be maximized by building intermoda connectivity of the transportation network that is more effective and efficient. It is also necessary to optimize connectivity in integrating the development phases of National, Provincial and District road sections. The network connectivity is expected to be able to encourage the production sector which is able to increase or develop production capacity, thus providing a more optimal multiplier impact in the future.
\end{abstract}

Keywords: input-output; multiplier income; the impact of the transportation sector; West Timor

\section{Pendahuluan}

Pulau Timor memiliki posisi strategis sebagai salah satu pulau yang dimiliki oleh dua negara yaitu Indonesia dan Timor Leste. Provinsi Nusa Tenggara Timur memiliki 1.192 pulau dan Timor Barat merupakan wilayah yang berbatasan darat dan laut dengan Timor Leste dan Australia. Hal ini menjadi keuntungan sekaligus tantangan karena Pulau Timor bagian Barat merupakan salah satu daerah miskin di Indonesia. Timor Barat memiliki jumlah penduduk 1.902.960 jiwa dengan angka kemiskinan tahun 2017 sebesar 20,25\% dibandingkan dengan Provinsi Nusa Tenggara Timur sebesar 21,77 \%. Sedangkan angka kemiskinan Nasional sebesar 10,15 \%. Penduduk Timor Barat yang bermukim di perdesaan sebesar 70,74\%, sedangkan yang bermukim di perkotaan sebesar 29,26 \% (BPS, 2018) .

Posisi strategis Timor Barat yang berbatasan darat dengan negara Timor Leste, menyebabkan tingginya aktivitas pergerakan orang, barang dan jasa. Interaksi dengan wilayah sekitar tersebut menurut Farhadi (2015) dan Agbelie (2014) harus didorong dengan peningkatan pembangunan sektor transportasi agar dapat meningkatkan produktivitas dan kenaikan output ekonomi. Keuntungan yang diperoleh dengan mengembangkan sektor transportasi yaitu: (1) mendukung terjadinya percepatan akses terhadap layanan, meningkatkan mobilitas pasar, menghemat waktu dan mengurangi biaya bisnis, kemudahan akses pasar dan bahan baku, dan pengurangan kemacetan. Hal ini memungkinkan negara-negara untuk meningkatkan keunggulan komparatif ekonomi mereka; (2) adanya peningkatan produk domestik bruto dan pendapatan pribadi serta penurunan tingkat pengangguran; serta (3) tersedianya kondisi yang lebih efektif untuk ekspansi ekonomi. Namun kondisi tersebut akan kondusif dalam memberi dampak positif, apabila dialokasikan biaya pembangunan transportasi secara tepat pada jenis moda dan infrastruktur transportasi yang tepat. 
Sektor transportasi merupakan input perantara dalam proses produksi, secara tidak langsung mempengaruhi pertumbuhan yang ditentukan oleh tiga faktor, yaitu: Pertama, produktivitas modal fisik yang ditentukan oleh efisiensi biaya dan pemeliharaan infrastruktur. Kedua adalah produktivitas tenaga kerja yang lebih tinggi yang diperoleh dari peningkatan kapasitas sumber daya manusia, dan ketiga adalah eksternalitas yang mentransmisikan inovasi teknologi yang menyebabkan biaya lebih rendah, dan efek lebih pada perusahaan lain dan pada ekonomi secara keseluruhan. Infrastruktur transportasi sebagai kontributor pembangunan ekonomi memiliki dampak spasial yang penting, misalnya pada intraregional dan antardaerah waktu dan biaya transportasi, dan berpengaruh pada lokasi rumah tangga dan bisnis (Ehizuelen, 2016; Anas et al. 2015).

Sektor transportasi di Timor Barat didominasi oleh angkutan darat dan angkutan laut sebesar $98 \%$. Anggaran untuk pembangunan infrastruktur transportasi dari tahun 20132018 terus mengalami peningkatan walaupun kenyataannya masih sangat kecil dibandingkan kebutuhan untuk memenuhi kelayakan minimal infrastruktur transportasi di Timor Barat. Besarnya biaya infrastruktur tersebut apabila diproksi dengan seluruh belanja modal kabupaten/kota di Timor Barat sebesar Rp. 1.333.689.837,53 ternyata baru sebesar $3,02 \%$ dari PDRB di Timor Barat. Sedangkan jalan nasional sepanjang 418,15 km atau sebesar 2,84 \% dari luas wilayah Timor Barat. Jalan provinsi di Timor Barat sepanjang $755,47 \mathrm{~km}$ atau 5,13 \% dari luas wilayah dan jalan kabupaten sepanjang 4.997,26 km atau sebesar 33,92 \% dari luas wilayah Timor Barat. Geografi dan topografi Timor Barat yang berbukit, dikelilingi sungai yang kering di musim kemarau dan banjir di musim penghujan, serta cenderung curam, menambah kompleksnya pembangunan infrastruktur transportasi.

Pertumbuhan infrastruktur transportasi di Timor Barat meningkat pesat dalam dekade akhir ini berupa peningkatan infrastruktur jalan, namun laju kerusakan jalan juga besar. Perubahan kondisi jalan rata-rata dari tahun 2002-2017 di Timor Barat, yaitu jalan kondisi baik 1,62 \%, jalan kondisi sedang $-1,73 \%$, jalan kondisi rusak meningkat $10,14 \%$ dan jalan kondisi rusak sekali meningkat $42,76 \%$. Jalan nasional dan jalan kabupaten mengalami peningkatan yang positif, sedangkan jalan provinsi mengalami penurunan sebesar $-2,98 \%$. Apabila dibandingkan dengan tingkat kerusakan jalan di Timor Barat dari tahun 2002-2017 yang mengalami kerusakan dan rusak sekali sebesar 52,90 \%. Sedangkan pertumbuhan kendaraan di Timor Barat beberapa tahun terakhir sebesar $8-9 \%$. Jumlah sarana transportasi berupa kendaraan pada tahun 2017 yaitu mobil penumpang sebanyak 19.961 unit, bus sebanyak 756 unit dan truk 15.460 unit atau total seluruh kendaraan sebanyak 36.177 atau sebesar 54,7\% dari keseluruhan kendaraan yang berada di Provinsi Nusa Tenggara Timur (NTT). Adapun jaringan jalan dan pelabuhan di Timor Barat sebagaimana pada Gambar 1.

Aktivitas pelabuhan laut juga meningkat pesat seperti pelabuhan laut Tenau atau disebut pelabuhan laut Nusa Lontar sebagai pelabuhan laut internasional, Pelabuhan Atapupu di Kabupaten Belu, dan Pelabuhan Wini di Kabupaten Timor Tengah Utara. Secara nasional sudah ada kebijakan maritim melalui tol laut yang direncanakan terintegrasi dengan sistem transportasi laut dengan pulau-pulau kecil di wilayah NTT. Pembangunan infrastruktur laut di Timor Barat sejak tahun 2002-2017 terus mengalami pertumbuhan. Laju pertumbuhan bongkar hewan meningkat rata-rata sebesar 3.213,84\% sedangkan untuk muat hewan hanya bertumbuh sebesar 1,12 \%. Bongkar barang/kargo juga masih lebih besar dari muat barang/kargo. Pertumbuhan jumlah kapal sebesar 19,62\% dan luas dermaga meningkat 2,19\%. Penumpang yang datang bertumbuh 6,43\% sedangkan yang berangkat $4,59 \%$.

Pembangunan transportasi di Timor Barat selayaknya pembangunan di negaranegara berkembang lainnya sering terkendala oleh keterbatasan biaya. Untuk itu diperlukan strategi pembangunan dengan memberikan prioritas bagi sektor-sektor sektor unggulan. Sektor unggulan adalah industri unggulan yang diharapkan menjadi industri penggerak 
utama dalam pembangunan. Pembangunan yang lebih difokuskan pada sektor unggulan secara tepat akan memberikan multiplier effect yang besar terhadap sektor-sektor lainnya, baik sektor-sektor yang ada di hulu (backward effect) maupun yang ada di hilir (forward effect). Penentuan sektor unggulan sangat diperlukan, karena investasi pada sektor unggulan tersebut akan memberikan multipler effect yang besar terhadap pembangunan di suatu negara.

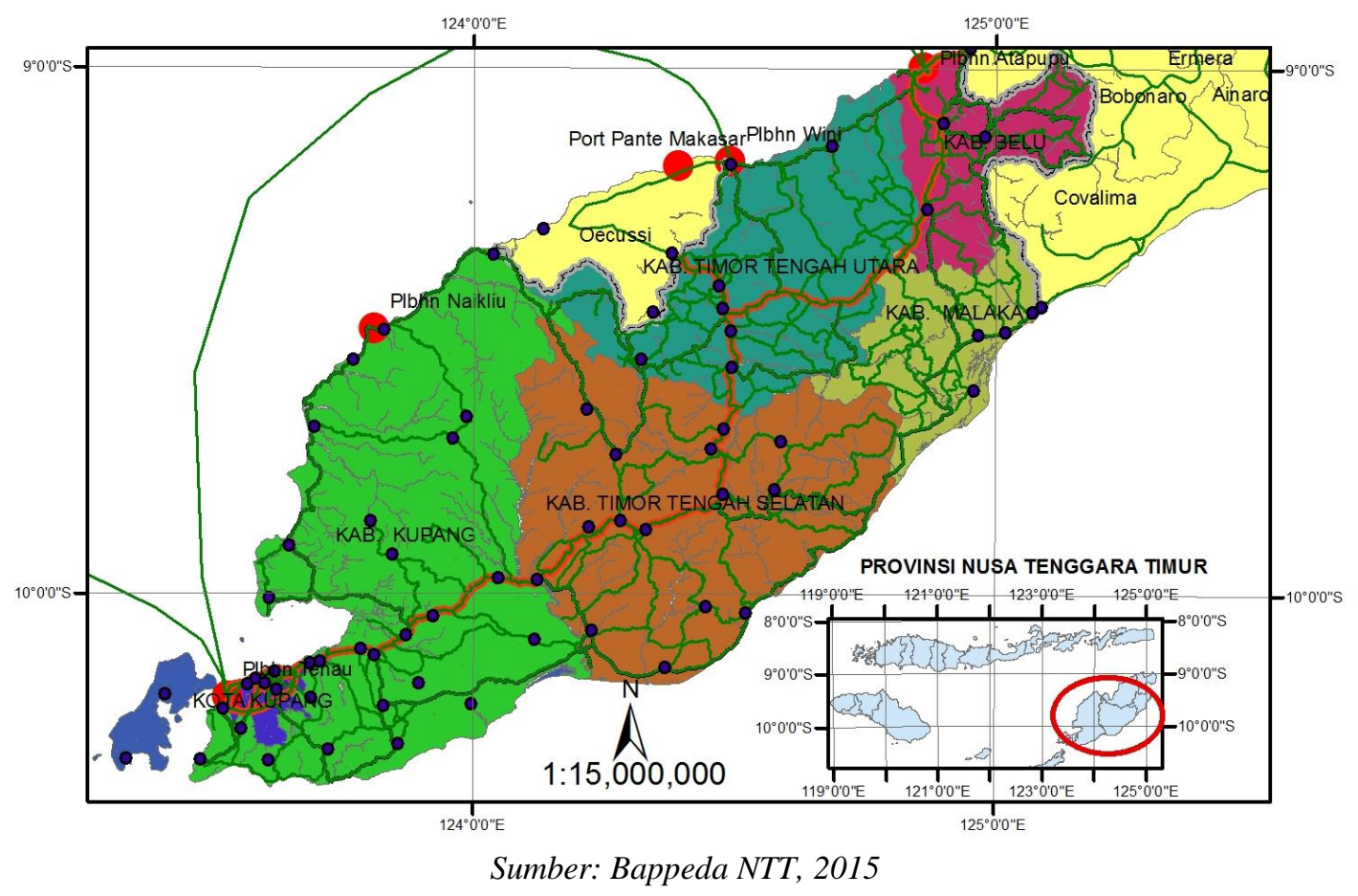

\section{Gambar 1. Peta Jaringan Jalan dan Pelabuhan di Timor Barat}

Pemerintahan yang berhasil adalah pemerintahan yang mampu menciptakan keterpaduan antarsektor dalam kerangka pembangunan wilayah. Keterpaduan tersebut menjadi landasan pengintegrasian sistem neraca produksi, sistem neraca konsumsi, baik secara regional, nasional maupun internasional. Keterpaduan dalam perspektif neraca produksi dari sudut pandang sistem industri adalah keterpaduan sistem input-output industri yang efisien dan sinergis secara spasial, serta menghasilkan sektor strategis yang memiliki dampak langsung dan tidak langsung yang signifikan. Karakteristik ekonomi wilayah yang ditunjukkan dengan distribusi sumbangan sektoral serta keterkaitan sektoral perekonomian wilayah, dapat dijelaskan melalui analisis input-output (Rustiadi et al., 2011).

Rustiadi et al. (2011) menjelaskan bahwa wilayah dipandang sebagai suatu sistem ekonomi, sektor transportasi dikembangkan untuk memfasilitasi sistem aliran sumber daya (informasi, barang dan jasa) yang efisien, meningkatkan produktivitas, dan mendorong interaksi spasial yang saling memperkuat (reinforcing each other). Untuk itu sistem transportasi diperlukan agar menciptakan aliran input-output (sumber daya manusia, energi, modal, serta barang-barang dan jasa lainnya) secara lintas sektor industri antarwilayah. Itulah sebabnya Ehizuelen (2016) menyadur pepatah populer China yang menyatakan bahwa "untuk menjadi kaya, pertama-tama harus membangun jalan" artinya bahwa tanpa sektor transportasi yang baik pembangunan ekonomi tidak bisa berjalan.

Diketahui dengan baik bahwa terdapat hubungan antara transportasi dan ekonomi (Perkins et al. 2005; Kodongo \& Ojah 2016), tetapi hubungan ini kompleks karena pertumbuhan ekonomi bukan satu-satunya faktor yang menentukan tren angkutan barang. 
Efek seperti inovasi teknologi, perubahan permintaan akhir atau peningkatan logistik juga dapat berkontribusi untuk mengubah pola transportasi (Alises \& Vassallo 2016). termasuk pertumbuhan ekonomi yang mempengaruhi transportasi dengan menggunakan model yang berbeda. Infrastruktur transportasi menurut Skorobogatova \& Kuzmina-Merlino (2017) merupakan bagian integral dari sistem transportasi kota atau negara.

Analisis input-output (I-O) memberikan informasi yang sangat berharga bagi perencanaan pembangunan daerah. Selain informasi mengenai keterkaitan struktural antarsektor perekonomian juga dapat memberikan arahan di dalam menetapkan sektorsektor prioritas di dalam pembangunan wilayah (Rustiadi et al., 2011). Analisis input-output juga bisa mengidentifikasi sektor apa saja yang cepat tumbuh, serta keterkaitan antarsektor dan konsep multiplier di wilayah yang dianalisis. Penggunaan model I-O nasional di dalam analisis ekonomi belum dapat memperlihatkan peranan dari masing-masing daerah dan adanya saling ketergantungan antar daerah, sehingga perlu dikembangkan untuk dapat merekam perekonomian lintas daerah (Priyarsono et al., 2007).

Penelitian dengan menggunakan metode analisis input-ouput telah dikembangkan sejak jaman Phsyokrat pada pertengahan abad ke-18. Puncak perkembangan Tabel I-O mencapai bentuk mendasari Tabel I-O Modern oleh Leontief (Rustiadi et al., 2011). Hingga kini hampir semua negara telah menyusun dan menggunakan tabel I-O. Kajian penelitian semakin kompleks dan memberi fokus pada penggunaan model I-O. Beberapa sektor dan subsektor ekonomi menggunakan analisis I-O antara lain penelitian tentang: sektor pertanian (Widyawati, 2017), sektor pariwisata merupakan sektor yang tercepat pertumbuhannya, menyumbang lebih dari sepertiga perdagangan jasa di seluruh dunia (Arianti 2017, Atan \& Arslanturk 2012); sektor infrastruktur (Sukma, 2015) dan transportasi (Anas et al. 2015, Muryani \& Swastika 2018, Wang \& Charles 2010, Alises \& Vassallo 2016); sektor rumah tangga telah menjadi konsumen energi final terbesar kedua, setelah sektor industri di Cina (Ding et al., 2017); tenaga kerja (Sauian et al., 2013), peternakan (Zuhdi et al., 2014); air bersih (Tian et al., 2019); analisis untuk mendapatkan sektor-sektor unggulan (Sutrisna et al., 2019), sektor industri dan pengolahan (Hilman \& Ester 2018; Mardiantony \& Ciptomulyono 2012), serta aspek lingkungan (Kjaer et al., 2015) .

Penelitian sebelumnya lebih banyak berfokus pada aktivitas sektor transportasi yang hanya berada pada lingkup wilayah administrasi berupa negara, provinsi atau kabupaten. Sedangkan penelitian ini menjadi menarik karena berfokus pada wilayah Pulau yaitu Timor Barat yang terdiri dari enam kabupaten dan kota. Timor Barat sebagai daerah marginal di Timur Indonesia. Penelitian ini bertujuan untuk mengkaji dampak ke belakang, dampak ke depan, serta dampak pengganda pembangunan di Timor Barat pada tahun 2018.

\section{Metode Penelitian}

Penelitian dilaksanakan pada instansi pusat dan Provinsi Nusa Tenggara Timur. Penelitian ini menggunakan data sekunder sebagian besar tersedia langsung pada kantor BPS Pusat, dan BPS Nusa Tenggara Timur (NTT), serta dapat diperoleh melalui internet. Untuk memperoleh data tambahan dan gambaran kondisi perekonomian Timor Barat maka peneliti juga mendatangi instansi BPS Pusat dan Provinsi NTT, Dinas Pekerjaan Umum Provinsi NTT; Kementerian Pekerjaan Umum; Data pengembangan dermaga/pelabuhan oleh Dinas Perhubungan serta dari Pelindo III pelabuhan laut Tenau Kupang. Selain memperoleh data I-O nasional tahun 2010, I-O Provinsi NTT 2006, dan data perekonomian lainnya, penulis juga mendapatkan data infrastruktur jalan (jalan nasional, jalan provinsi, dan jalan kabupaten) di Timor Barat berupa data infrastruktur jalan di Kabupaten Kupang, Kota Kupang, Kabupaten Timor Tengah Selatan, Kabupaten Timor Tengah Utara, Kabupaten Belu dan Kabupaten Malaka, serta pelabuhan laut Tenau Kupang, Pelabuhan Wini di Kabupaten Timor Tengah Utara dan pelabuhan Atapupu di Kabupaten Belu. Data 


\section{Dampak Sektor Transportasi Terhadap Perekonomian di Timor Barat ...}

primer sebagian kondisi jalan dan pelabuhan, serta aktivitas ekonomi di perbatasan darat antara negara dengan Timor Leste di Timor Barat.

Penelitian ini melakukan penaksiran matriks teknologi dengan metode nonsurvei yaitu dengan menggunakan metode RAS. Penaksiran matriks teknologi Timor Barat tahun 2018 berdasarkan matriks teknologi NTT 2006. Dari 55 sektor tahun 2006 (55 x 55) sektor menjadi 18 sektor ekonomi. Metode RAS tersebut untuk mendapatkan data dasar inputoutput NTT dan data dasar input-output Timor Barat tahun 2018. Analisis dalam membangun tabel input-output selain melalui metode nonsurvei antara lain: regional supply percentage method, location quotient method, dan metode RAS.

\section{Tahapan RAS}

Metode RAS sebagaimana penelitian Parikh (1979); Trinh \& Phong (2013) dan Holý \& Šafr (2020). Tahapan metode RAS yang pertama yaitu menentukan matriks teknologi pada periode I, yaitu $\mathrm{A}(\mathrm{I})$, menentukan matriks teknologi pada tahun asal; $\mathrm{A}(0)$, menentukan jumlah output sektoral pada periode yang dicari, notasikan dengan $\mathrm{X}(1)$. Kemudian tentukan kolom transaksi input-output pada periode yang dicari dan dinotasikan $\mathrm{V}(1)$, yang menyatakan jumlah output seluruh sektor yang digunakan sebagai input untuk memproduksi sektor. Kedua, menentukan baris transaksi input-output pada periode yang dicari dan dinotasikan $\mathrm{U}(1)$, yang menyatakan jumlah output sektor 1 yang digunakan sebagai input produksi oleh seluruh sektor. Nilai X(1), V(1), dan $\mathrm{U}(1)$ diperoleh dari survei parsial. Ketiga, menentukan kriteria kekonvergenan yaitu $\varepsilon \leq 0.00001$. Keempat, menentukan perbandingan nilai $\mathrm{U} 1$ dengan $\mathrm{U}(1)$, yang diharapkan yaitu $|\mathrm{U} 1-\mathrm{U}(1)| \leq \varepsilon$. Jika kondisi tersebut tidak terjadi maka harus dilakukan penyesuaian. Kelima, mengestimasikan matriks teknologi $\mathrm{A} 1=\mathrm{R} 1 \mathrm{~A}(0)$. Keenam, menentukan dan membandingkan nilai $\mathrm{V} 1$ dengan $\mathrm{V}(1)$, yang diharapkan yaitu $|\mathrm{V} 1-\mathrm{V}(1)| \leq \varepsilon$. Jika kondisi tersebut tidak terjadi maka harus dilakukan penyesuaian. Ketujuh, mengestimasikan matriks teknologi yaitu $\mathrm{A} 2=\mathrm{A} 1 \mathrm{~S} 1=\mathrm{R} 1 \mathrm{~A}(0) \mathrm{S} 1$. Kedelapan, melakukan pengecekan, seperti tahapan keempat atau keenam, sampai terpenuhi kriteria pada tahapan ketiga.

Jika prosedur metode RAS terus berlanjut maka akan diperoleh: $\mathrm{A} 3=$ $\mathrm{R} 2 \mathrm{~A} 2=[\mathrm{R} 2 \mathrm{R} 1] \mathrm{A}(0) \mathrm{S} 1 ; \mathrm{A} 4=\mathrm{A} 3 \mathrm{~S} 2=\mathrm{R} 2 \mathrm{~A} 2 \mathrm{~S} 2=[\mathrm{R} 2 \mathrm{R} 1] \mathrm{A}(0)[\mathrm{S} 1 \mathrm{~S} 2] ; \mathrm{A} 5=[\mathrm{R} 3 \mathrm{R} 2 \mathrm{R} 1] \mathrm{A}(0)[\mathrm{S} 1 \mathrm{~S} 2]$; $\mathrm{A} 6=[\mathrm{R} 3 \mathrm{R} 2 \mathrm{R} 1] \mathrm{A}(0)[\mathrm{S} 1 \mathrm{~S} 2 \mathrm{~S} 3]$, sampai $\mathrm{A} 2 \mathrm{n}=[\mathrm{Rn} . . \mathrm{R} 3 \mathrm{R} 2 \mathrm{R} 1] \mathrm{A}(0)[\mathrm{S} 1 \mathrm{~S} 2 \mathrm{~S} 3 \ldots \mathrm{Sn}] ; \mathrm{A} 2 \mathrm{n}+1$ $=[\mathrm{Rn}+1 \ldots \mathrm{R} 3 \mathrm{R} 2 \mathrm{R} 1] \mathrm{A}(0)$ [S1S2S3...Sn]. Matriks Teknologi (Matriks Koefisien Input-Output) I-O NTT tahun 2006 dan Agregasi matriks perekonomian NTT tahun 2006 terdiri dari 55 sektor ekonomi. Matriks teknologi memiliki variabel-variabel input antara (Z), output (X), permintaan akhir (Y) dan variabel input primer (W). Ke-empat variabel tersebut jika diuraikan dalam bentuk matriks dengan: $C=$ konsumsi rumah tangga, $G=$ belanja pemerintah, $\mathrm{I}=$ investasi $\mathrm{E}=$ ekspor, $\mathrm{L}=$ tenaga kerja, dan $\mathrm{N}=$ nilai tambah.

\section{Analisis Input-Ouput}

Penelitian ini menggunakan analisis input-output sebagai pendekatan metodologinya. Pendekatan ini mengkaji hubungan antara berbagai arus sektor dalam perekonomian, yang menampilkan adanya hubungan saling ketergantungan antara produsen dan konsumen serta antar industri. Analisis ini juga dapat melacak aliran komoditas (barang dan jasa) dari sektor transportasi ke industri lain. Alur komoditas yang disediakan dan digunakan disusun secara sistematis dalam bentuk tabel input-output (BPS 2010; Sauian et al. 2013; Anas et al. 2015). Analisis input-output menelaah hubungan antarsektor, yang terlibat, pertautan, investasi, dan perbaikan serta antisipasi pembelian dan permintaan. Analisis input-output menjelaskan karakteristik ekonomi wilayah yang ditunjukkan dengan distribusi sumbangan sektoral serta keterkaitan sektoral perekonomian wilayah. Model Leontief didasarkan atas model keseimbangan umum (general equilibrium). (Priyarsono et al. 2007; Jhinghan, 2016; 
Muryani \& Swastika 2018).

Analisis I-O mampu menggambarkan keterkaitan antarsektor di dalam perekonomian dan dapat mengetahui multiplier effect atas suatu kegiatan ekonomi sektoral. Namun dalam pemanfaatannya memiliki beberapa keterbatasan yaitu: (1) tidak memodelkan pengaruh perubahan harga dalam perekonomian, hanya memodelkan hubungan kuantitas; (2) asumsi rasio input-output konstan sepanjang periode analisis, sehingga tidak memungkinkan terjadinya substitusi dalam perekonomian; dan (3) adanya batasan (lack of supply constrain) dan tidak adanya respon harga. Oleh karena itu, ada tiga asumsi dasar dalam analisis I-O, yaitu: homogenitas, proporsianilitas dan aditivitas (Rustiadi et al. 2011; Priyarsono et al. 2007; Amir \& Nugroho 2019).

Tabel I-O berdasarkan baris dan kolom. Isian baris menunjukkan struktur permintaan (demand) atas output yang dihasilkan oleh suatu sektor. Output yang dihasilkan oleh suatu sektor akan dialokasikan untuk memenuhi permintaan antara (permintaan bahan baku produksi sektor lain), maupun permintaan akhir/dikonsumsi (rumah tangga, pemerintah, investasi, perubahan stok, dan ekspor). Penjumlahan baris merupakan nilai output suatu sektor. Isian kolom menggambarkan struktur produksi dari masing-masing sektor (supply). Input tersebut dapat berupa input antara (bahan baku produksi) maupun input primer atau biaya konversi (upah gaji, surplus, usaha, penyusutan, pajak tidak langsung, dan subsidi). Penjumlahan dari suatu kolom menunjukkan nilai input dari suatu sektor. Dalam Tabel I-O nilai input dari suatu sektor harus sama dengan nilai outputnya (Priyarsono et al. 2007; Amir \& Nugroho 2019). Tabel I-O dapat diperluas dengan data emisi dari masing-masing sektor, sehingga dapat menghitung dampak siklus hidup dari belanja untuk setiap pengeluaran produk. Model I-O yang diperluas dengan memasukkan aspek lingkungan disebut sebagai analisis Environmental Input-Output (EIO) (Kjaer et al., 2015), yang belum dapat dibahas dalam tulisan ini. Adapun ilustrasi tabel I-O sebagaimana ditampilkan pada Tabel 1.

Tabel 1. Ilustrasi Tabel Input-Output

\begin{tabular}{|c|c|c|c|c|c|c|c|c|c|}
\hline \multirow{3}{*}{\multicolumn{2}{|c|}{$\underbrace{\text { Alokasi Output }}_{\substack{\text { Susunan } \\
\text { Input }}}$}} & & & Permi & aan & tara & & \multirow{3}{*}{$\begin{array}{c}\text { Permintaan } \\
\text { Akhir }\end{array}$} & \multirow{3}{*}{$\begin{array}{c}\text { Total } \\
\text { Output }\end{array}$} \\
\hline & & & \multicolumn{5}{|c|}{ Sektor Produksi } & & \\
\hline & & & 1 & 2 & 3 & $\ldots$ & n & & \\
\hline \multirow{7}{*}{\multicolumn{2}{|c|}{ 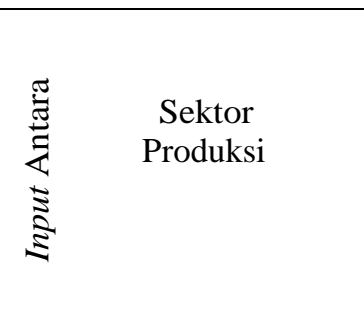 }} & 1 & $\mathrm{x} 11$ & $\mathrm{x} 12$ & $\mathrm{x} 13$ & $\ldots$ & $\mathrm{x} 1 \mathrm{n}$ & $\mathrm{F}_{1} \mathrm{~F}_{2} \mathrm{~F}_{3}$ & $\mathrm{X}_{1}$ \\
\hline & & 2 & $\mathrm{x} 21$ & x 22 & $\mathrm{x} 23$ & $\ldots$ & $x 2 n$ & . & $X_{2}$ \\
\hline & & 3 & $\mathrm{x} 31$ & x32 & $\mathrm{x} 33$ & $\ldots$ & $x 3 n$ & \multirow{5}{*}{$\mathrm{F}_{\mathrm{n}}$} & $X_{3}$ \\
\hline & & . & . & . & . & $\ldots$ & & & . \\
\hline & & . & . & . & . & $\ldots$ & . & & . \\
\hline & & . & . & . & . & $\cdots$ & . & & \\
\hline & & $\mathrm{n}$ & $\mathrm{x}_{\mathrm{n} 1}$ & $x_{n} 2$ & . & $\cdots$ & $x_{n n}$ & & $X_{n}$ \\
\hline \multicolumn{3}{|c|}{ Total Input Primer } & $\mathrm{V}_{1}$ & $\mathrm{~V}_{2}$ & $\mathrm{~V}_{3}$ & $\ldots$ & $\mathrm{V}_{\mathrm{n}}$ & & \\
\hline \multicolumn{3}{|c|}{ Total Input } & $\mathrm{X}_{1}$ & $\mathrm{X}_{2}$ & $\mathrm{X}_{3}$ & $\ldots$ & $X_{n}$ & & \\
\hline
\end{tabular}

Sumber: Diadaptasi dari Rustiadi et al., 2011; BPS, 2010

\section{Keterkaitan Antarsektor Ekonomi dan Dampak Berganda}

Untuk menghitung daya penyebaran terlebih dahulu menghitung hubungan antara output dan permintaan akhir dapat dijabarkan sebagai $\mathrm{X}=(\mathrm{I}-\mathrm{A})^{-1} \mathrm{~F}$. X adalah vektor kolom dari output, $\mathrm{F}$ adalah vektor kolom dari permintaan akhir. Jumlah daya penyebaran atau dapat disebut sebagai dampak akibat perubahan permintaan akhir suatu sektor terhadap output seluruh sektor ekonomi (rj) dapat dirumuskan sebagai: $r_{j}=b_{1 j}+b_{2 j} \ldots+b_{n j}=\Sigma_{i} b_{i j}$. Selanjutnya dinormalkan (normalized) dengan cara membagi rata-rata dampak suatu sektor 
dengan rata-rata dampak seluruh sektor. Ukuran yang dinormalkan ini dinamakan dengan indeks daya penyebaran $\left(\alpha_{\mathrm{j}}\right)$ atau tingkat dampak keterkaitan ke belakang (backward linkages effect ratio), dengan menggunakan persamaan (1).

$$
\alpha_{i}=\frac{\sum_{i} b_{i}}{\left(\frac{1}{n}\right) \sum \sum_{i} b_{i}}
$$

$\alpha_{\mathrm{j}}=1$ daya penyebaran sektor $\mathrm{j}$ sama dengan rata-rata daya penyebaran seluruh sektor ekonomi; $\alpha_{j}>1$ daya penyebaran sektor $\mathrm{j}$ di atas rata-rata daya penyebaran seluruh sektor ekonomi; $\alpha_{j}<1$ daya penyebaran sektor $\mathrm{j}$ di bawah rata-rata daya penyebaran seluruh sektor ekonomi.

Dari persamaan (1) untuk menghitung derajat kepekaan maka dapat dilihat jumlah dampak output suatu sektor i sebagai akibat perubahan permintaan akhir seluruh sektor, yang dapat dirumuskan sebagai: $\mathrm{s}_{\mathrm{j}}=\Sigma_{\mathrm{j}} \mathrm{b}_{\mathrm{ij}}$. Nilai $\mathrm{s}_{\mathrm{j}}$ disebut dengan jumlah derajat kepekaan, merupakan ukuran untuk melihat keterkaitan ke depan (forward linkage) sektor-sektor ekonomi di suatu wilayah. Untuk menghitung indeks derajat kepekaan $\left(\beta_{\mathrm{i}}\right)$ menggunakan persamaan (2).

$$
\beta_{i}=\frac{\sum_{i}^{b_{i}}}{\left(\frac{1}{n}\right) \sum_{i} \sum_{i} b_{i}}
$$

Keterangan: $\beta_{\mathrm{i}}=1$ derajat kepekaan sektor $\mathrm{j}$ sama dengan rata-rata derajat kepekaan seluruh sektor ekonomi; $\beta_{\mathrm{i}}>1$ derajat kepekaan sektor $\mathrm{j}$ di atas rata-rata derajat kepekaan seluruh sektor ekonomi; $\beta_{\mathrm{i}}<1$ derajat kepekaan sektor $\mathrm{j}$ di bawah rata-rata derajat kepekaan seluruh sektor ekonomi.

Dampak multiplier menurut Sutrisna et al. (2019), merupakan dampak total akibat pengaruh luar dalam berbagai jenis kegiatan ekonomi. Dalam model I-O efek pengali dihitung dari matriks invers Leontief. Ukuran pengali tergantung pada seberapa jauh dan seberapa intens interaksi ekonomi antarsektor. Output dari Dampak pengganda diperoleh dari penjumlahan pengali keluaran langsung dan tidak langsung. Menghitung matriks pengganda (B) dan total pengganda. Matriks pengganda (B) dihitung dengan cara menginverskan matriks yang diperoleh pada tahap 2 di atas $\left(B=(I-A)^{-1}\right)$. Sedangkan dampak permintaan akhir terhadap output, dapat digunakan rumus: $\mathrm{X}=(\mathrm{I}-\mathrm{A})^{-1} \mathrm{~F}$. Yang berarti bahwa matriks pengganda dikalikan dengan matriks permintaan akhir, seperti ditampilkan pada persamaan (3).

$$
\alpha_{i}=\frac{\sum_{i} b_{i}}{\left(\frac{1}{n}\right) \sum \sum_{i} b_{i j}}
$$

\section{Hasil dan Pembahasan}

Kerangka analisis struktur ekonomi mikro dan makro dijelaskan secara baik dengan menggunakan pendekatan I-O. Analisis I-O juga sangat mumpuni menggambarkan 
keterkaitan antarsektor di dalam perekonomian. Hubungan antarsektor dalam perekonomian dalam bentuk hubungan supply dan demand, produsen dan konsumen, input dan output (Amir \& Nugroho, 2019).

\section{Dampak ke Belakang}

Sektor transportasi di Timor Barat memiliki keterkaitan ke belakang (backward linkage) yaitu keterkaitan langsung ke belakang (direct backward linkage) dan keterkaitan tidak langsung ke belakang (indirect backward linkage). Keterkaitan antarsektor ekonomi ini dipergunakan untuk perumusan strategi pembangunan. Keterkaitan langsung ke belakang didapat dari koefisien input (matriks teknologi), sedangkan keterkaitan tidak langsung ke belakang diperoleh dari matriks kebalikan Leontief terbuka.

Parameter ini menunjukkan bahwa permintaan suatu sektor terhadap perubahan tingkat produksi sektor-sektor yang menyediakan input antara bagi sektor tersebut secara langsung. Kaitan ke belakang langsung dan tidak langsung (indirect backward lingkage/IBL) menunjukkan kenaikan permintaan akhir satu unit sektor tertentu yang dapat meningkatkan total output seluruh sektor perekonomian (Rustiadi et al., 2011). Hal ini dapat dilihat pada Tabel 2. Hasil analisis keterkaitan ke belakang menurut rangking sektor ekonomi di Timor Barat tahun 2018 diperoleh bahwa sektor transportasi termasuk sektor strategis yaitu sebesar 1,400 berada di urutan 4 dari 18 sektor.

Tabel 1. Hasil Analisis Keterkaitan ke Belakang Menurut Rangking Sektor Ekonomi di Timor Barat Tahun 2018

\begin{tabular}{|c|c|c|c|c|c|c|}
\hline \multirow{2}{*}{ Peringkat } & \multirow{2}{*}{ Sektor } & \multirow{2}{*}{ Kode } & \multicolumn{4}{|c|}{ Keterkaitan Ke belakang } \\
\hline & & & DBL & DIBL & SDBL & SDIBL \\
\hline 1 & $\begin{array}{l}\text { Industri pengolahan dan pengawetan } \\
\text { makan \& minuman }\end{array}$ & 8 & 0,878 & 2,980 & 2,926 & 1,803 \\
\hline 2 & Bangunan & 10 & 0,655 & 2,549 & 2,186 & 1,542 \\
\hline 3 & Listrik, gas, uap, dan air bersih & 9 & 0,575 & 1,959 & 1,918 & 1,185 \\
\hline 4 & Transportasi dan Pergudangan & 12 & 0,479 & 2,314 & 1,599 & 1,400 \\
\hline 5 & Jasa lainnya & 18 & 0,347 & 1,992 & 1,156 & 1,205 \\
\hline 6 & $\begin{array}{l}\text { Usaha bangunan, Real estate, dan jasa } \\
\text { perusahaan }\end{array}$ & 16 & 0,290 & 1,490 & 0,967 & 0,902 \\
\hline 7 & Pertambangan dan Penggalian & 7 & 0,278 & 1,317 & 0,928 & 0,797 \\
\hline 8 & Bank dan Lembaga Keuangan lain & 15 & 0,249 & 1,359 & 0,830 & 0,822 \\
\hline 9 & Sayur \& tanaman bahan makanan & 2 & 0,243 & 1,734 & 0,810 & 1,049 \\
\hline 10 & $\begin{array}{l}\text { Jasa administrasi pemerintahan dan } \\
\text { pertahanan, kegt sosial dan jasa } \\
\text { perorangan }\end{array}$ & 17 & 0,204 & 1,525 & 0,681 & 0,922 \\
\hline 11 & Perikanan & 6 & 0,190 & 1,478 & 0,634 & 0,894 \\
\hline 12 & Kelapa, Kopi, \& Jambu Mete & 3 & 0,177 & 1,391 & 0,591 & 0,842 \\
\hline 13 & $\begin{array}{l}\text { Penyedia Akomodasi dan makan } \\
\text { minum }\end{array}$ & 13 & 0,176 & 1,510 & 0,586 & 0,914 \\
\hline 14 & Peternakan & 4 & 0,175 & 1,513 & 0,583 & 0,915 \\
\hline 15 & Kayu \& hasil hutan lainnya & 5 & 0,155 & 1,273 & 0,516 & 0,770 \\
\hline
\end{tabular}

Besarnya tingkat keterkaitan ke belakang (backward linkage) atau disebut juga daya penyebaran. Sektor yang mempunyai daya penyebaran tinggi menunjukkan indikasi bahwa sektor tersebut merupakan sektor yang strategis dalam memacu pertumbuhan ekonomi. Indeks derajat penyebaran (Standardize direct indirect bakward lingkage/SDIBL) tertinggi adalah sektor industri pengolahan dan pengawetan makan dan minuman yaitu sebesar 1,803 . Ini menunjukkan bahwa setiap kenaikan 1 unit output sektor 
industri pengolahan dan pengawetan makan dan minuman perdagangan, maka akan menyebabkan naiknya output sektor-sektor lainnya (termasuk sektor industri pengolahan dan pengawetan makan dan minuman sendiri) secara keseluruhan sebesar 1,803 unit.

\section{Dampak ke Depan}

Kaitan langsung ke depan (direct forward linkage) sebagai salah satu parameter teknis dalam analisis input-output. Parameter ini menunjukkan output suatu sektor yang dipakai oleh sektor-sektor keterkaitan ke depan (forward linkage) antarsektor ekonomi yang digunakan sebagai dasar perumusan strategi pembangunan ekonomi. Kaitan ke depan langsung dan tidak langsung (indirect forward lingkage) menunjukkan peranan satu sektor dapat memenuhi permintaan akhir dari seluruh sektor perekonomian (Rustiadi et al., 2011). Hasil analisisnya sebagaimana Tabel 3. bahwa sektor transportasi memiliki indeks kepekaan yang relatif rendah yaitu sebesar 0,486, sehingga berada pada rangking 15 besar dari 18 sektor, untuk nilai indeks derajat kepekaan (Standardize direct indirect forward lingkage/SDIFL).

Tabel 3. Hasil Analisis Keterkaitan ke Depan Menurut Rangking Sektor Skonomi di Timor Barat Tahun 2018

\begin{tabular}{|c|c|c|c|c|c|c|}
\hline \multirow{2}{*}{ Peringkat } & \multirow{2}{*}{ Sektor } & \multirow{2}{*}{ Kode } & \multicolumn{4}{|c|}{ Keterkaitan Ke Depan } \\
\hline & & & DFL & DIFL & SDFL & SDIFL \\
\hline 1 & $\begin{array}{l}\text { Industri pengolahan dan pengawetan } \\
\text { makan \& minuman }\end{array}$ & 8 & 3,654 & 8,049 & 12,185 & 4.87 \\
\hline 2 & Bank dan Lembaga Keuangan lain & 15 & 0,784 & 2,559 & 2,616 & 1.548 \\
\hline 3 & Padi, Jagung, Kacang \& Umbi2an & 1 & 0,250 & 2,430 & 0,834 & 1.47 \\
\hline 4 & $\begin{array}{l}\text { Usaha bangunan, Real Estate, dan } \\
\text { jasa perusahaan }\end{array}$ & 16 & 0,983 & 2,208 & 3,279 & 1.336 \\
\hline 5 & Komunikasi & 14 & 0,633 & 1,808 & 2,112 & 1.094 \\
\hline 6 & Kelapa, Kopi, \& Jambu Mete & 3 & 0,214 & 1,687 & 0,715 & 1.021 \\
\hline 7 & Perikanan & 6 & 0,139 & 1,669 & 0,463 & 1.01 \\
\hline 8 & Kayu \& hasil hutan lainnya & 5 & 0,079 & 1,393 & 0,265 & 0.843 \\
\hline 9 & Sayur \& tanaman bahan makanan & 2 & 0,123 & 1,152 & 0,411 & 0.697 \\
\hline 10 & $\begin{array}{l}\text { Jasa administrasi pemerintahan dan } \\
\text { pertahanan, kegt sosial dan jasa } \\
\text { perorangan }\end{array}$ & 17 & 0,060 & 1,085 & 0,198 & 0.657 \\
\hline 11 & Pertambangan dan Penggalian & 7 & 0,064 & 1,020 & 0,213 & 0.617 \\
\hline 12 & Perdagangan & 11 & 0 & 1,000 & 0 & 0.605 \\
\hline 13 & $\begin{array}{l}\text { Penyedia Akomodasi dan makan } \\
\text { minum }\end{array}$ & 13 & $-0,018$ & 0,980 & $-0,061$ & 0.593 \\
\hline 14 & Listrik, gas, uap, dan air bersih & 9 & $-0,025$ & 0,951 & $-0,082$ & 0.576 \\
\hline 15 & Transportasi dan Pergudangan & 12 & $-0,161$ & 0,803 & $-0,538$ & 0.486 \\
\hline
\end{tabular}

Hal ini berarti bahwa setiap kenaikan 1 unit output sektor transportasi, maka akan mendorong sektor- sektor yang menggunakan sektor transportasi sebagai input akan naik sebesar 0,486 unit. Nilai tertinggi adalah sektor industri pengolahan dan pengawetan makan dan minuman dengan nilai indeks derajat kepekaan sebesar 4,870.

Hasil analisis dari Tabel 2 dan Tabel 3 apabila digabungkan maka akan mendapatkan urutan sektor-sektor yang merupakan sektor unggulan, potensial, berkembang dan terbelakang. Sektor unggulan adalah sektor yang memiliki keterkaitan ke belakang dan ke depan di atas nilai 1; Sektor potensial adalah sektor yang memiliki keterkaitan ke belakang di atas nilai 1 sedangkan keterkaitan ke depan di bawah nilai 1; Sektor berkembang adalah sektor yang memiliki keterkaitan ke belakang di bawah nilai 1 sedangkan keterkaitan ke 
depan di atas nilai 1. Sektor yang termasuk kategori terbelakang adalah sektor yang memiliki keterkaitan ke depan dan ke belakang di bawah nilai 1. Adapun rangking dari kategori tersebut sebagaimana Tabel 4.

Sektor unggulan di Timor Barat sebagaimana pada Tabel 4 adalah sektor industri pengolahan dan pengawetan makan dan minuman. Sektor ini sebagai sektor pemimpin yang mendorong permintaan agregat (aggregate demand) yang lebih tinggi dan meningkatkan penawaran agregat (aggregate supply) untuk pemenuhan kebutuhan domestik. Hal ini sesuai penelitian Hilman \& Ester (2018) bahwa industri pengolahan di antaranya adalah sub sektor pengolahan makanan dan minuman merupakan sektor yang cukup unggul dalam sektor perekonomian Indonesia, baik dilihat melalui pertumbuhannya maupun melalui kontribusinya terhadap pendapatan nasional. industri tersebut menjadi motor penggerak utama sektor industri pengolahan non-migas dengan total rata-rata kontribusi selama tahun 2014-2017 sebesar 76,3 persen.

Tabel 2. Kategorial Sektor-Sektor Ekonomi di Timor Barat Tahun 2018

\begin{tabular}{|c|c|c|c|c|c|}
\hline Peringkat & Sektor & Kode & SDIBL & SDIFL & Kategori \\
\hline 1 & $\begin{array}{l}\text { Industri pengolahan dan pengawetan } \\
\text { makan \& minuman }\end{array}$ & 8 & 1.803 & 4.87 & Unggulan \\
\hline 2 & Bangunan & 10 & 1.542 & -0.281 & Potensial \\
\hline 3 & Listrik, gas, uap, dan air bersih & 9 & 1.185 & 0.567 & Potensial \\
\hline 4 & Transportasi dan Pergudangan & 12 & 1.4 & 0.486 & Potensial \\
\hline 5 & Jasa lainnya & 18 & 1.205 & 0.458 & Potensial \\
\hline 6 & Sayur \& tanaman bahan makanan & 2 & 1.049 & 0.697 & Potensial \\
\hline 7 & $\begin{array}{l}\text { Usaha bangunan, Real Estate, dan jasa } \\
\text { perusahaan }\end{array}$ & 16 & 0.902 & 1.336 & Berkembang \\
\hline 8 & Bank dan Lembaga Keuangan lain & 15 & 0.822 & 1.548 & Berkembang \\
\hline 9 & Perikanan & 6 & 0.894 & 1.01 & Berkembang \\
\hline 10 & Kelapa, Kopi, \& Jambu Mete & 3 & 0.842 & 1.021 & Berkembang \\
\hline 11 & Padi, Jagung, Kacang \& Umbi2an & 1 & 0.742 & 1.47 & Berkembang \\
\hline 12 & Komunikasi & 14 & 0.621 & 1.094 & Berkembang \\
\hline 13 & Pertambangan dan Penggalian & 7 & 0.797 & 0.617 & Terbelakang \\
\hline 14 & $\begin{array}{l}\text { Jasa administrasi pemerintahan dan } \\
\text { pertahanan, kegiatan sosial dan jasa } \\
\text { perorangan }\end{array}$ & 17 & 0.922 & 0.657 & Terbelakang \\
\hline 15 & Penyedia Akomodasi dan makan minum & 13 & 0.914 & 0.593 & Terbelakang \\
\hline 16 & Peternakan & 4 & 0.915 & 0.376 & Terbelakang \\
\hline 17 & Kayu \& hasil hutan lainnya & 5 & 0.77 & 0.843 & Terbelakang \\
\hline 18 & Perdagangan & 11 & 0.673 & 0.605 & Terbelakang \\
\hline
\end{tabular}

Sektor transportasi merupakan sektor potensial yang masih harus dibenahi secara terintegrasi dengan sektor-sektor lainnya baik sektor hulu maupun sektor hilir. Sektor transportasi memiliki daya penyebaran yang tinggi mengindikasi bahwa sektor tersebut adalah sektor strategis dalam memacu pertumbuhan ekonomi. Namun dampak ke depan yang masih rendah yaitu masih rendahnya kemampuan untuk menyuplai sektor-sektor produksi lainnya. Hal ini hampir sama dengan penelitian Muryani \& Swastika (2018) bahwa angkutan memiliki total linkage ke belakang yang tinggi sedangkan total linkage ke depan relatif rendah. Ini merupakan indikasi bahwa transportasi secara keseluruhan di Indonesia telah memberi dampak terhadap pengembangan sektor hulu, tetapi belum berperan optimal dalam pengembangan sektor hilir.

Sektor transportasi di Timor Barat belum mendukung sektor hilir secara optimal. Hal ini bisa dipahami bahwa kondisi jalan di Timor Barat yang mengalami laju kerusakan yang 
besar yaitu 52,90 \%, dan pelabuhan bongkar muat hewan yang lebih banyak bongkar dari pada muat. Infrastruktur transportasi jalan yang mengalami kerusakan tanpa pembenahan yang berarti oleh pemerintah setiap tahunnya. Timor Barat mengalami darurat infrastruktur transportasi atau defisit infrastruktur, sehingga perlu ada terobosan dan penanganan luar biasa dari pemerintah di Provinsi Nusa Tenggara Timur ke depan. Anggaran infrastruktur dan pembenahan kualitas infrastruktur menjadi prioritas penanganannya. Menurut Maparu \& Mazumder (2017) bahwa daerah pedalaman yang terisolasi apabila terhubung melalui jaringan transportasi ke pusat-pusat ekonomi, maka daerah tersebut akan cepat berkembang, serta mengurangi disparitas regional. Hal ini menunjukkan bahwa infrastruktur transportasi dan pembangunan ekonomi saling terkait dan penting untuk dikembangkan di Timor Barat.

Penelitian oleh Perkins et al. (2005) bahwa investasi infrastruktur tidak akan berdampak bagi pertumbuhan ekonomi apabila dana infrastruktur tidak mencukupi untuk pengembangan infrastruktur yang efektif. Oleh karena itu pembuat kebijakan (policy maker) harus fokus dalam memilih atau mendukung tipe infrastruktur yang tepat pada waktu yang tepat pula. Penelitian peningkatan akses infrastruktur terhadap pertumbuhan ekonomi Afrika, dilihat dari peningkatan kualitas infrastruktur, secara statistik tidak signifikan mengingat rendahnya kualitas dan endowment infrastruktur yang rendah di benua ini (Kodongo \& Ojah, 2016). Begitu juga menurut Meersman \& Nazemzadeh (2017) bahwa pembangunan infrastruktur sering terkendala oleh minimnya dana yang disediakan oleh pemerintah untuk mendorong sektor transportasi menjadi sektor unggulan.

\section{Dampak Pengganda (Multiplier Effect)}

Multiplier adalah koefisien yang menyatakan kelipatan dampak langsung dan tidak langsung dari meningkatnya permintaan akhir suatu sektor sebesar satu unit terhadap aspek-aspek tertentu ekonomi suatu wilayah (Rustiadi et al., 2011). Hasil analisis sebagaimana Tabel 5 .

Hasil analisis pada Tabel 5 untuk Timor Barat diperoleh bahwa nilai dampak terhadap gaji dan upah (income multiplier) tertinggi pada sektor industri pengolahan dan pengawetan makanan-minuman sebesar 6,080 serta sektor transportasi sebesar 2,069. Dampak terhadap nilai tambah total (total value added multiplier) tertinggi berada pada sektor peternakan sebesar 8,170 , sedangkan sektor transportasi memiliki nilai tambah total sebesar 1,409.

Berdasarkan hasil penelitian ini berarti bahwa, besarnya dampak income multiplier sektor transportasi sebesar 1 unit satuan adalah meningkatnya total output produksi semua sektor sebesar 2,069 unit satuan. Sedangkan meningkatnya permintaan akhir pada sektor transportasi akan meningkatkan PDRB sebesar 1,409 kali. Sebagaimana penelitian Muryani \& Swastika (2018) bahwa multiplier effect sektor transportasi memiliki nilai yang tinggi, sedangkan pengganda pendapatan dan pengganda tenaga kerjanya rendah. Hal ini menunjukkan bahwa perubahan anggaran di sektor transportasi dapat mengubah output produksi perekonomian Indonesia, namun perubahan anggaran kurang berpengaruh terhadap pendapatan dan penyerapan tenaga kerja.

Sektor peternakan memiliki total value added multiplier tertinggi, artinya bahwa dampak meningkatnya permintaan akhir pada sektor peternakan akan meningkatkan PDRB sebesar 8,170 kali. Padahal hasil analisis juga menunjukkan bahwa peternakan termasuk kategori sektor terbelakang di urutan ke 16 di Timor Barat. Menurut Zuhdi et al. (2014) bahwa dampak peternakan di Jepang oleh karena adanya peningkatan konsumsi rumah tangga di luar Jepang mendorong peningkatan total output sektor peternakan, dengan cara menekan impor ternak. Pembatasan impor dibarengi dengan kegiatan lain untuk memenuhi kebutuhan produksi peternakan di Jepang. Untuk itu pangsa pasar konsumsi luar Timor Barat melalui program nasional tol laut perlu dimanfaatkan secara optimal, agar dapat 
mengekspor sapi ke luar daerah Timor dalam mencukupi kebutuhan sapi nasional, dengan tetap dapat mencukupi kebutuhan dalam daerah.

Tabel 3. Dampak Pengganda Sektor-Sektor Ekonomi di Timor Barat

\begin{tabular}{|c|c|c|c|c|c|c|}
\hline Sektor & Rangking & $\begin{array}{l}\text { Income } \\
\text { Multi- } \\
\text { plier }\end{array}$ & $\begin{array}{l}\text { Business } \\
\text { Surplus } \\
\text { Multi- } \\
\text { plier }\end{array}$ & $\begin{array}{l}\text { Depreciation } \\
\text { Multi-plier }\end{array}$ & $\begin{array}{l}\text { Value } \\
\text { Added } \\
\text { Tax } \\
\text { Multi- } \\
\text { plier } \\
\end{array}$ & $\begin{array}{c}\text { Total } \\
\text { Value- } \\
\text { Added } \\
\text { Multi- } \\
\text { plier }\end{array}$ \\
\hline & & IM & $\mathbf{S M}$ & $\mathbf{D M}$ & TM & VM \\
\hline $\begin{array}{l}\text { Industri pengolahan dan pengawetan } \\
\text { makan \& minuman }\end{array}$ & 1 & 6,08 & 9,359 & 12,871 & 6,612 & 1,921 \\
\hline Bangunan & 2 & 2,379 & 3,397 & 2,633 & 2,015 & 1,135 \\
\hline Transportasi dan Pergudangan & 3 & 2,069 & 2,105 & 1,132 & 1,695 & 1,409 \\
\hline $\begin{array}{l}\text { Usaha bangunan, Real estate, dan jasa } \\
\text { perusahaan }\end{array}$ & 4 & 1,796 & 1,37 & 1,153 & 1,04 & 0 \\
\hline Listrik, gas, uap, dan air bersih & 5 & 1,539 & 5,845 & 1,515 & 7,54 & 1,213 \\
\hline Sayur \& tanaman bahan makanan & 6 & 1,369 & 1,305 & 1,871 & 1,3 & 1,235 \\
\hline Perikanan & 7 & 1,329 & 1,217 & 1,161 & 1,255 & 2,902 \\
\hline Bank dan Lembaga Keuangan lain & 8 & 1,316 & 1,334 & 1,392 & 1,536 & 1,725 \\
\hline Pertambangan dan Penggalian & 9 & 1,305 & 1,425 & 1,31 & 1,705 & 1,085 \\
\hline Jasa lainnya & 10 & 1,29 & 1,818 & 1,306 & 1,777 & 0 \\
\hline Kelapa, Kopi, \& Jambu Mete & 11 & 1,29 & 1,2 & 1,239 & 1,231 & 1,386 \\
\hline Peternakan & 12 & 1,204 & 1,217 & 1,189 & 1,166 & 8,17 \\
\hline Perdagangan & 13 & 1,177 & 1,067 & 1,039 & 1,018 & 1,331 \\
\hline $\begin{array}{l}\text { Penyedia Akomodasi dan makan } \\
\text { minum }\end{array}$ & 14 & 1,173 & 1,278 & 1,085 & 1,031 & 1,257 \\
\hline Kayu \& hasil hutan lainnya & 15 & 1,164 & 1,181 & 1,233 & 2,278 & 2,354 \\
\hline Padi, Jagung, Kacang \& Umbi2an & 16 & 1,147 & 1,146 & 1,249 & 1,179 & 1,183 \\
\hline Komunikasi & 17 & 1,142 & 1,124 & 1,166 & 1,17 & 1,53 \\
\hline $\begin{array}{l}\text { Jasa administrasi pemerintahan dan } \\
\text { pertahanan, kegt sosial dan jasa } \\
\text { perorangan }\end{array}$ & 18 & 1,082 & 9,353 & 1,125 & 2,329 & 0 \\
\hline
\end{tabular}

\section{Kesimpulan}

Besarnya tingkat keterkaitan langsung ke belakang (direct indirect backward linkage) Sektor transportasi di Timor Barat sebesar 1,400 berada di urutan 4 dari 18 sektor. Hal ini berarti bahwa sektor transportasi merupakan sektor potensial yang layak untuk dikembangkan untuk mendorong pengembangan sektor hilir. Besarnya keterkaitan langsung ke depan (direct indirect forward linkage) sebesar 0,486. Total nilai dampak berganda sektor transportasi sebesar 1,409 masih di bawah sektor industri pengolahan dan pengawetan makanan-minuman, sektor perikanan dan sektor peternakan. Sektor peternakan memberi nilai dampak berganda tertinggi yaitu sebesar 8,170. Hal ini menjadi menarik karena sektor peternakan walaupun memiliki dampak berganda yang paling tinggi, namun hanya berada pada urutan 16 sektor dan merupakan sektor terbelakang di Timor Barat.

Sektor transportasi perlu dioptimalkan agar ke depan dapat mendukung sektor-sektor lainnya, sehingga dapat memusatkan industri regional, memacu pembangunan ekonomi regional, memperkuat sistem transportasi yang lebih luas, meningkatkan investasi dan akhirnya meningkatkan perekonomian demi kesejahteraan masyarakat. Sektor transportasi di Timor Barat dikembangkan dengan memperhatikan keterkaitan dengan sektor peternakan serta sektor Industri pengolahan dan pengawetan makanan-minuman. Kebijakan sektor transportasi oleh pemerintah Provinsi Nusa Tenggara Timur di Timor 
Barat perlu dilakukan dengan mengakses lokasi-lokasi potensial peternakan yang terisolasi, sehingga terhubung ke pasar dan pelabuhan.

Perlu ada penelitian lebih dalam keterkaitan sektor transportasi, sektor Industri pengolahan dan pengawetan makanan-minuman, serta sektor peternakan agar layak dikembangkan menjadi sektor unggulan di Timor Barat. Penelitian ke depan juga penting memasukkan aspek lingkungan untuk memperkaya kajian sektor transportasi, dengan memperhatikan kondisi lingkungan di Timor Barat yang gersang dan kurang subur. Penulis merekomendasi penelitian lanjutan model I-O di Timor Barat yang diperluas dengan memasukkan aspek lingkungan yaitu analisis Environmental Input-Output (EIO).

\section{Daftar Pustaka}

Agbelie, B. R. D. K. (2014). An empirical analysis of three econometric frameworks for evaluating economic impacts of transportation infrastructure expenditures across countries. Transport Policy, 35, 304-310. doi:10.1016/j.tranpol.2014.06.009.

Alises, A., \& Vassallo, J. M. (2016). The impact of the structure of the economy on the evolution of road freight transport: A macro analysis from an input-output approach. Transportation Research Procedia, 14, 28702879. doi:10.1016/j.trpro.2016.05.404.

Amir, H dan Nugroho, A. (2019). Seri analisis kebijakan fiskal, analisis dampak kebijakan menggunakan model Computable General Equilibrium (CGE). Jakarta: PT. Gramedia Pustaka Utama.

Anas, R., Tamin, O. Z., \& Wibowo, S. S. (2015). Applying input-output model to estimate the broader economic benefits of Cipularang Tollroad Investment to Bandung District. Procedia Engineering, 125, 489-497. doi:10.1016/j.proeng.2015.11.042.

Arianti, D. (2014). Pengaruh sektor pariwisata terhadap perekonomian dan keruangan Kota Bukittinggi (pendekatan analisis input output). Jurnal Wilayah dan Lingkungan, 2(3), 183-196. doi:10.14710/jwl.2.3.183-196.

Atan, S., \& Arslanturk, Y. (2012). Tourism and economic growth nexus: An input output analysis in Turkey. Procedia - Social and Behavioral Sciences, 62, 952-956. doi:10.1016/j.sbspro.2012.09.162.

Badan Pusat Statistik (BPS). (2010). Tabel input ouput Indonesia 2010. Badan Pusat Statistik.

Badan Pusat Statistik (BPS). (2018). Provinsi NTT dalam angka dan Kabupaten/Kota di Timor Barat dalam angka (Tahun 2003-2018). Badan Pusat Statistik.

Bappeda Nusa Tenggara Timur. (2015). Revisi Rencana Tata Ruang Wilayah Nusa Tenggara Timur 2010-2030. Bappeda Nusa Tenggara Timur.

Ding, Q., Cai, W., \& Wang, C. (2017). Impact of household consumption activities on energy consumption in China - Evidence from the lifestyle perspective and input-output analysis. Energy Procedia, 105, 33843390. doi:10.1016/j.egypro.2017.03.767.

Ehizuelen, M. M. O. (2016). The dynamics of infrastructure and economic growth in Nigeria. Journal of Global Economics, 4(1), 1-9. doi:10.4172/2375-4389.1000169.

Farhadi, M. (2015). Transport infrastructure and long-run economic growth in OECD countries. Transportation Research Part A, 74, 73-90. doi:10.1016/j.tra.2015.02.006.

Hilman, A. M., \& Ester, A. M. (2018). Peranan sektor industri pengolahan dalam perekonomian Indonesia: Model input-output. Media Ekonomi, 26(1), 63-76. doi:10.25105/me.v26i1.5210.

Holý, V., \& Šafr, K. (2020). Disaggregating input-output tables by the multidimensional RAS Method. 1-17. Retrieved from http://arxiv.org/abs/1704.07814.

Jhinghan, M. L. (2016). Ekonomi pembangunan dan perencanaan. Jakarta: Rajawali Pers.

Kjaer, L. L., Høst-madsen, N. K., Schmidt, J. H., \& Mcaloone, T. C. (2015). Application of environmental inputoutput analysis for corporate and product environmental footprints-learnings from three cases. Sustainability, 79), 11438-11461. doi: 10.3390/su70911438.

Kodongo, O., \& Ojah, K. (2016). Does infrastructure really explain economic growth in Sub-Saharan Africa? Review of Development Finance, 6(2), 105-125. doi:10.1016/j.rdf.2016.12.001. 
Maparu, T. S., \& Mazumder, T. N. (2017). Transport infrastructure, economic development and urbanization in India (1990-2011): Is there any causal relationship? Transportation Research Part A: Policy and Practice, 100, 319-336. doi:10.1016/j.tra.2017.04.033.

Mardiantony, T., \& Ciptomulyono, U. (2012). Penerapan analisis input output dan anp dalam penentuan prioritas pengembangan sub sektor industri di Jawa Timur. Jurnal Teknik ITS, 1(1), 456-459. doi:10.12962/j23373539.v1i1.1531.

Meersman, H., \& Nazemzadeh, M. (2017). The contribution of transport infrastructure to economic activity: The case of Belgium. Case Studies on Transport Policy, 5(2), 316-324. doi:10.1016/j.cstp.2017.03.009.

Muryani, M \& Swastika, R. B. (2018). Input-output analysis: A case study of transportation sector in Indonesia. JDE (Journal of Developing Economies), 3(2), 80-90. doi:10.20473/jde.v3i2.9650.

Parikh, A. (1979). Forecasts of input-output matrices using the R.A.S. method. The Review of Economics and Statistics, 61(3), 477-481. doi:10.2307/1926084.

Perkins, P., Fedderke, J., \& Luiz, J. (2005). An analysis of economic infrastructure investment in South Africa. South African Journal of Economics, 73(2), 211-228. doi:10.1111/j.1813-6982.2005.00014.x.

Priyarsono, D. S., Sahara, \& Firdaus, M. (2007). Ekonomi Regional. Jakarta: Universitas Terbuka.

Rustiadi, E., Saefulhakim, S., \& Panuju, D. R. (2011). Perencanaan dan pengembangan wilayah. Jakarta: Crestpent Press dan Yayasan Pusataka Obor Indonesia.

Sauian, M. S., Kamarudin, N., \& Rani, R. M. (2013). Labor productivity of services sector in Malaysia: Analysis using input-output approach. Procedia Economics and Finance, 7, 35-41. doi:10.1016/S22125671(13)00215-3.

Skorobogatova, O., \& Kuzmina-Merlino, I. (2017). Transport infrastructure development performance. Procedia Engineering, 178, 319-329. doi:10.1016/j.proeng.2017.01.056.

Sukma, A. F. (2015). Efek pengganda infrastruktur pekerjaan umum dalam perekonomian Provinsi Bali. Jurnal Perencanaan Wilayah dan Kota, 26(2), 100-110. doi:10.5614/jpwk.2015.26.2.3.

Sutrisna, M. G., Sitorus, S. R. P., Widiatmaka, Marimin, \& Nurwajedi. (2019). Leading sector analysis in West Kotawaringin Regency, Central Kalimantan Province, Indonesia. IOP Conference Series: Earth and Environmental Science, 399(1). doi:10.1088/1755-1315/399/1/012068.

Tian, Z., Wang, S., \& Chen, B. (2019). A three-scale input-output analysis of blue and grey water footprint for Beijing-Tianjin-Hebei Urban Agglomeration. Energy Procedia, 158, 4049-4054. doi:10.1016/j.egypro.2019.01.833.

Trinh, B., \& Phong, N. V. (2013). A short note on RAS method. Advances in Management \& Applied Economics, 3, 133-137.

Wang, J., \& Charles, M. B. (2010). IO based impact analysis: A method for estimating the economic impacts by different transport infrastructure investments in Australia. ATRF 2010: 33rd Australasian Transport Research Forum (pp 1-24). Canberra, Australia: Australasian Transport Research Forum.

Widyawati, R. F. (2017). Analisis keterkaitan sektor pertanian dan pengaruhnya terhadap perekonomian Indonesia (analisis input ouput). Jurnal Economia, 13(1), 14-27. doi:10.21831/economia.v13i1.11923.

Zuhdi, U., Prasetyo, A. D., \& Putranto, N. A. R. (2014). Analyzing the changes of total output of Japanese livestock sector: an input - output approach. Procedia - Social and Behavioral Sciences, 109, 649-653. doi:10.1016/j.sbspro.2013.12.522. 